\title{
Materials used in automobile manufacture - current state and perspectives
}

\author{
M. WILHELM \\ Mercedes-Benz AG, ZWT/GA, 70322 Stuttgart, Germany
}

\begin{abstract}
The materials which are applied in modern motor vehicles can be considered to be optimally accommodated to the actual demands. Normally a change of materials is only required if by that a cost reduction can be realized, or if the demands change. Such changes at present or in the near future mainly concern ecological aspects: consumption reduction; weight reduction; low emission of pollutants by vehicles and in the production process; recycling of materials. Those materials in question which better accommodate the new requirements can be: improved variants of actually applied materials; fully developed materials approved already in other technical areas but not yet applied in automotive engineering; newly developed materials. Starting from the actual conception examples will be given for each category. They will show that the cost of future materials tend to be higher, but that even with more expensive materials sometimes the cost of a component can be reduced.
\end{abstract}

\section{INTRODUCTION}

Since materials play a decisive role with regard to both the quality and cost of a car, selection of the correct materials at the earliest possible stage of the development process is of vital importance.

The materials used in vehicles nowadays are selected so as to optimally fulfill the specific requirements. It is the job of the materials engineer in a car-manufacturing company to ensure that this optimum will be reached. However, the corporation, itself, must decide what "optimal" actually means in practice. As well as considering the general economic framework, external influences such as the customers selected as the target group, and legal requirements and regulations are particularly relevant here.

Newly developed or modified conventional materials on the market represent competition for materials already in use. The application potential of such materials is dependent on how well they satisfy the requirements placed on them. 


\section{DEMANDS MADE ON THE MATERIALS}

Fig. 1 shows the expectations placed on the automobile by customers and the social environment. The demands made on components and materials which result from such expectations are also shown. Where materials already in use optimally fulfill current requirements, there is little prospect of alternative materials gaining acceptance; however, in two situations they have a chance of displacing the existing materials:

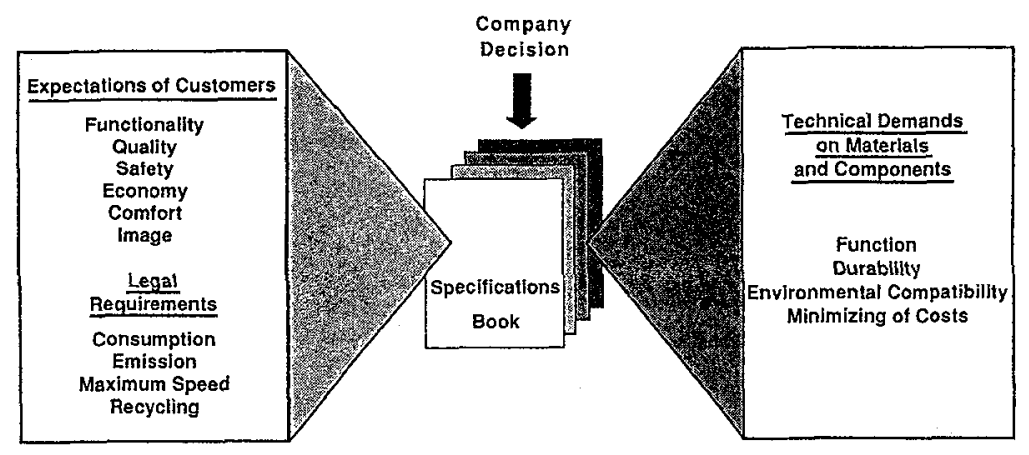

Fig. 1: Demands on a Motor Vehicle

1. Assuming that the demands remain unchanged, the existing material would only be replaced where such a measure also resulted in a cost reduction. In general, improved fulfillment of demands already adequately covered by the existing material - for example with regard to increased strength or better corrosion-resistance - does not represent a sufficient reason for a substitution.

2. Where requirements are modified and where these new requirements, including minimized cost, are not met by the conventional materials, the new materials are substituted for the old. Modified demands result from a change in the social and legal environment and/or a change in customer attitudes.

It has to be emphasized that fulfilling the requirements may not be seen under the isolated aspect of materials, but always must consider the completed part or component, including design and manufacturing aspects.

The current distribution of automobile materials with respect to the total weight is shown in Fig. 2 as is a projection to the year 2000 . The reasons for the probable shifts in proportions are discussed below. To understand future developments, it is necessary to analyze how demands on the automobile will change in future years. 


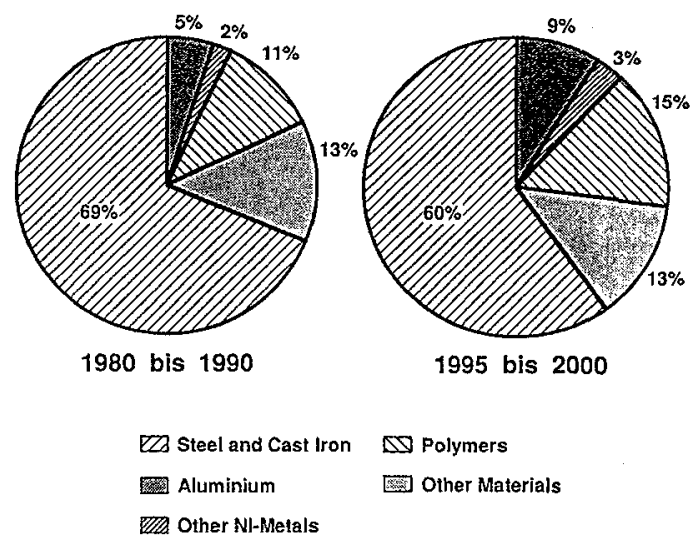

Fig. 2: Estimated Materials Application in the German Automotive Industry

For the foreseeable future, ecological requirements emerging from the social and legal environment - the need to protect the natural environment and use resources sparingly - will almost certainly represent a major factor for change. Fig. 3 illustrates how these demands will affect the processes and the materials used in automobile construction.

\begin{tabular}{|l|l|l|}
\hline $\begin{array}{l}\text { Requirements on } \\
\text { Automotive Industry }\end{array}$ & $\begin{array}{l}\text { Reaction of } \\
\text { Automotive Industry }\end{array}$ & $\begin{array}{l}\text { Significance of } \\
\text { Materials Engineering }\end{array}$ \\
\hline $\begin{array}{l}\text { Care of Ressources } \\
\text { Care of Envtronment }\end{array}$ & $\begin{array}{l}\text { Consumption Reduetion } \\
\text { Weight Reductlon }\end{array}$ & $\begin{array}{l}\text { Light Weight Materials } \\
\text { Materlals With Higher Effictency } \\
\text { Weight Ratio } \\
\text { Low-Friction Materlal Combinations }\end{array}$ \\
\cline { 2 - 4 } & $\begin{array}{l}\text { Reduction of Pollutant } \\
\text { Emlssion } \\
\text { of Vehicles } \\
\text { in the Production Process }\end{array}$ & $\begin{array}{l}\text { Non-Toxic Materials } \\
\text { Low Emission Processes }\end{array}$ \\
\cline { 2 - 4 } & $\begin{array}{l}\text { Closed Material Cycles } \\
\text { Price Reduction }\end{array}$ & $\begin{array}{l}\text { Recyclable Materials } \\
\text { Application of Recycled Polymers } \\
\text { Application of Renewabie } \\
\text { Organic Materials }\end{array}$ \\
\hline & $\begin{array}{l}\text { Cost Reduction in Development } \\
\text { and Production }\end{array}$ & $\begin{array}{l}\text { Low-Price Materials } \\
\text { Low-Cost Processes }\end{array}$ \\
\hline
\end{tabular}

Fig. 3: Requirements on Future Materials in the Automotive Industry

The sales price of the vehicle is assuming an ever increasing role in determining whether it actually gets sold. However, the choice of materials is increasingly influenced by factors other than the sales price: the aspect of costs incurred over the total life cycle, incorporating considerations such as consumption, maintenance and disposal of the automobile, being of particular relevance. 


\section{NEW OR ALTERNATIVE MATERIALS}

It is possible to divide possible alternatives to currently used materials into three categories:

- Materials already in use which can be improved and/or made cheaper through further development.

- Materials which have already been developed, but which have however not been used in automobile construction to date.

- Newly developed materials ("high-tech" materials).

Since development is a continuous process, a degree of overlap between categories is inevitable. Examples of the different groups of materials are given below.

\subsection{The further development of already widely-used materials.}

Even conventional automobile materials, like e.g. the metallic materials, are constantly improved. The new materials have a good chance to substitute for the current ones, because developers, materials engineers and production engineers are able to rely on available knowledge and experience. This means that the effect of each modification on quality, production requirements and costs, and thus the risks associated with a conversion, can be well estimated.

The success attainable in this manner can be impressively demonstrated using an example which could well be described as historic, even though developments are still in progress (Fig. 4). Lamellar cast iron is an inexpensive material possessing relatively modest strength and toughness properties. On the other hand, quenched and tempered steels can be produced in a broad range of strengths with very good ductility. For this reason, these steels were unrivaled in their suitability for highly-stressed automobile components for a long time. However, in general, the steel component cost is many times greater than that of a corresponding component made from lamellar cast iron. With the development of ductile iron it became possible for the foundries to offer a multitude of components, which although not capable of withstanding the same high degree of stress, could be produced at prices significantly lower than those of quenched and tempered steel. In turn, the realization that many components were still capable of fulfilling the specified requirements, even when the performance spectrum of their materials, especially the toughness, was reduced, led to the development of the economic AFP steels by the steel industry. In this manner, it was possible to brake the further conversion to ductile iron. In the meantime, quenched and tempered steels have disappeared from many areas of application in the automobile as a result of this development, which is still in progress.

A similar development can be observed for steels used in sheet forming. In this case, it has been the need for light-weight construction and not the pressure of cost-cutting that has been paramount in generating competition. The advantageous strength-to-weight ratio of the aluminium alloys and plastics is compensated in many cases for the higher strength and better deformation behaviour of the HSLA steel sheets (Fig. 5). Also for these steels the development to qualities with still higher strength and at the same time high deformability is not yet finished. The requirements of each individual component with regard to strength, rigidity, ductility and ultimately economic considerations decide which of the materials is to be preferred. 


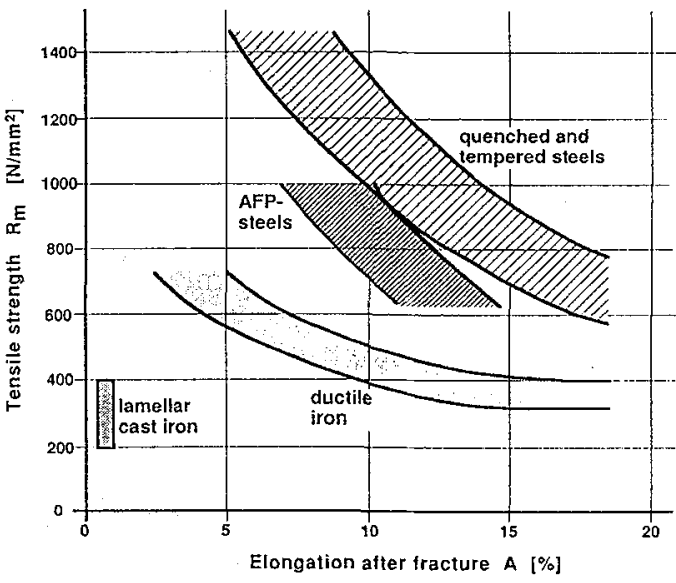

Fig. 4:Iron-Base-Materials for Automotive Components

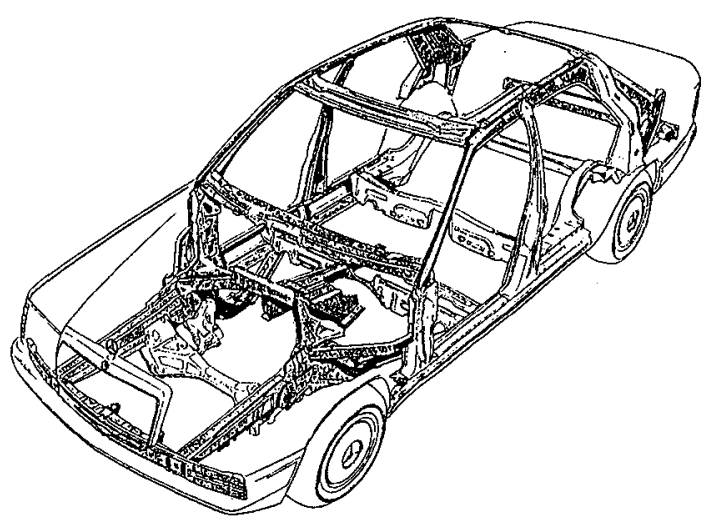

Fig. 5: Mercedes-Benz (W 124 model; as of 1985): Use of high-strength metal sheets (set off in grey)

The so-called "tailored blanks" are an interesting new development [1]. These are tailor-made semifinished products for deep-drawing parts, in which steel sheets of varying thicknesses, quality and surface treatment are joined by the steel producer (Fig. 6).

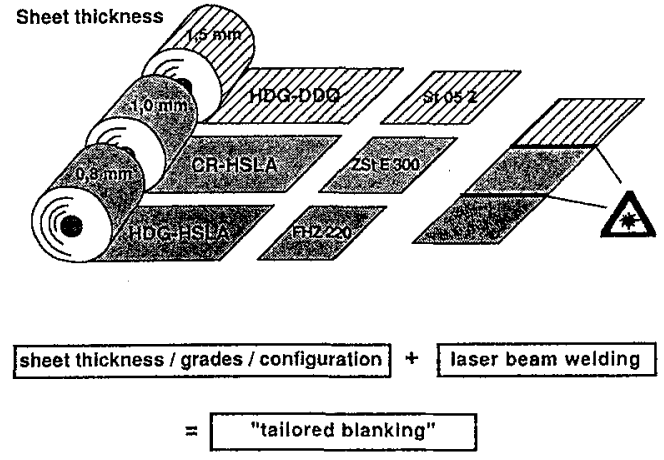

Fig. 6: Potential of "tailored blanking" (Source: Thyssen Stahl AG)

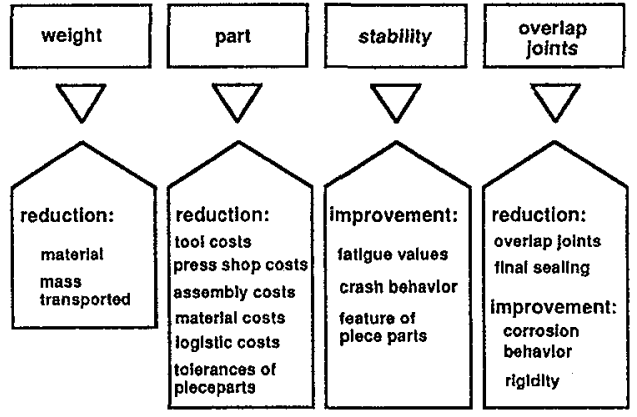

Fig. 7: Advantages of "tailored blanks" (Source: Thyssen Stahl AG)

The higher cost of these types of sheet metal is balanced by lower manufacturing costs, a possible weight reduction and improved component properties (Fig. 7). 
At present aluminium has assumed particular importance in the discussion about light-weight materials. As illustrated in Fig. 2, aluminium alloys have already found wide application in automobile manufacture. In particular with regard to the engine, transmission and axles, the possibilities offered by this material already appear to have been substantially exhausted. For this reason, attention has now been directed towards the chassis and the body. An increase in aluminium utilization seems possible here, for example in doors and hoods or in load-bearing structures (Fig. 8).

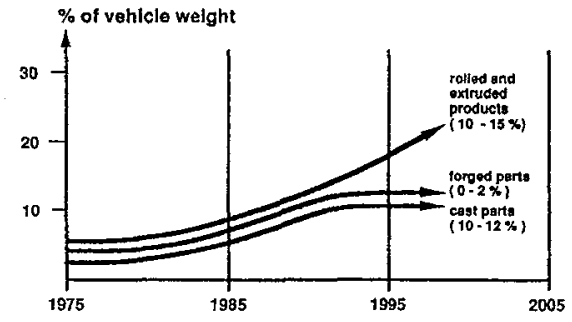

\begin{tabular}{|c|c|c|c|}
\hline phase & $\begin{array}{l}\text { simple substitution } \\
\text { of cast Iron } \\
\text { by cast afuminium }\end{array}$ & $\begin{array}{c}\text { systematlc search } \\
\text { for now } \\
\text { substlution } \\
\text { potential }\end{array}$ & $\begin{array}{l}\text { new design and } \\
\text { construction } \\
\text { principies, } \\
\text { application of } \\
\text { forged and } \\
\text { rolled products }\end{array}$ \\
\hline $\begin{array}{c}\text { typical } \\
\text { applications }\end{array}$ & $\begin{array}{l}\text { cyllnder head } \\
\text { crank case } \\
\text { geat-box }\end{array}$ & $\begin{array}{l}\text { engine mount } \\
\text { whegl cartier } \\
\text { seat frame }\end{array}$ & $\begin{array}{l}\text { chassis } \\
\text { body }\end{array}$ \\
\hline time Interval & \multicolumn{3}{|c|}{$5-10$ years per phase } \\
\hline
\end{tabular}

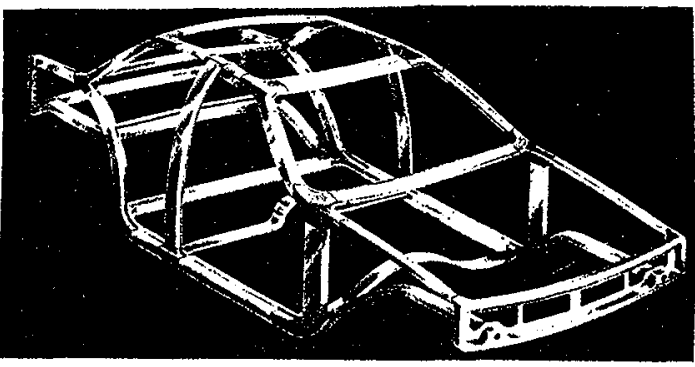

Fig. 8: Aluminium Application in the Automotive Industry (acc. McKinsey)

Fig. 9: Spaceframe Project Alcoa / Audi Al-Extrusion Profiles and Al-Cast Junctions joined by Fusion Welding; Weight Saving Compared to Conventional Construction ca. $35 \%$

The space-frame concept followed by some automobile manufacturers offers one such example (Fig. 9). Technical problems do however exist with regard to the joining of aluminium with other aluminium or steel components. Other difficulties are encountered with the corrosion resistance, especially in terms of protection against crevice corrosion and with the repair of damaged parts. The extent to which aluminium materials can be usefully employed in vehicle construction will not become clear until the emergence of the next generation of vehicles. Fiber-reinforced aluminium has found occasional application in motor components, e.g. as a reinforcement of the pistonhead.The development of totally new alloy types is not to be expected.

Magnesium is becoming increasingly relevant as a material. There are two principal reasons for this: its favorable ratio of strength to density and the ease with which it can be worked into complex thin-walled components using pressure diecasting. Fig. 10 shows a current example. The main problems with the utilization of this material are corrosion and recycling. Whereas the problem of general corrosion appears to have been substantially remedied by the development of the HP alloys, extensive construction isolation measures are still required to combat galvanic corrosion. Because of the small quantities occurring up to now, the recycling path of disassembly, collection according to type, remelting and casting into components of similar quality has not yet been developed. 


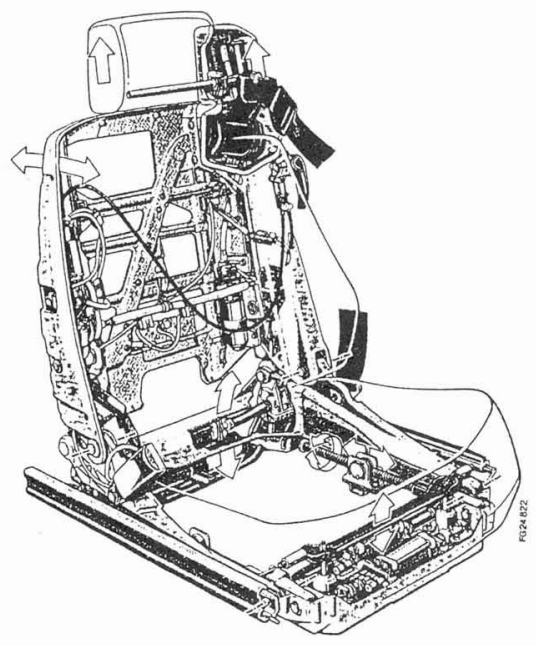

Fig. 10: Mercedes-Benz SL-Roadster: Integral seat with magnesium frame

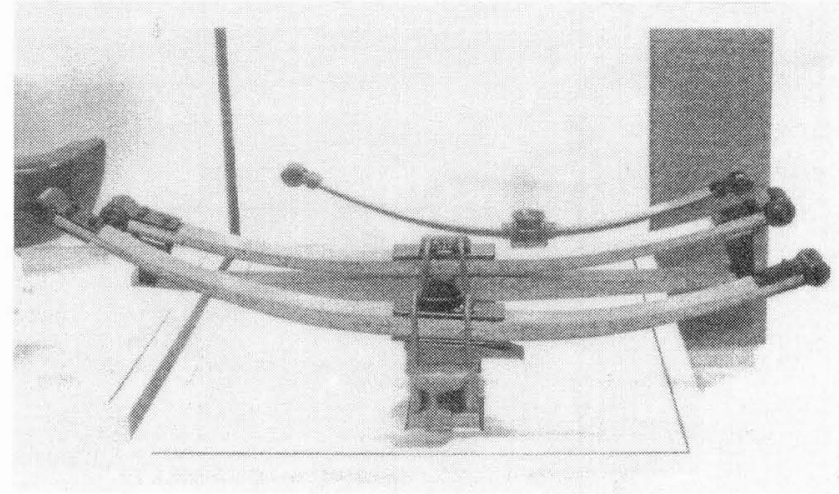

Fig. 11: GFRP Leaf Springs

\subsection{Conventional materials with potential for new applications in automobile manufacture}

Most of the materials discussed in this group are light-weight materials which have long found application in aircraft construction. The potential for applying these materials in automobile manufacture has increased, partly due to the demand for reduced consumption and therefore for light-weight construction, and partly thanks to improved and consequently more economical production techniques. $\mathrm{Al}$ - and $\mathrm{Mg}$-alloys have already been considered above. The mechanical properties of titanium are excellent in relation to its weight but its high price restricts its use to special applications such as connecting rods for racing engines.

Plastics are widely used in vehicles and still have a high potential for application in automotive engineering. Apart from the major reason, i.e. weight saving, one essential advantage is the opportunity to design highly complex component shapes. This allows optimum utilization of the increasingly restricted space for components in modern cars. Further use of plastics is currently hindered by open questions regarding used vehicle disposal and recycling.

Fibre-reinforced plastics can also be used in components subjected to high stresses. Fig. 11 shows an FRP leaf spring, which replaces steel leaf springs, reducing the weight of the spring by $60 \%$ and which has passed the required tests for commercial vehicles.

Even carbon fibre-reinforced plastics with strengths higher than steels, which are by far too expensive for mass-production components, can be used economically in special parts with a limited production. A progressive example is the cell construction of a bus manufactured as one part [2] (Fig. 12).

The expected trends for the further application of polymer materials in automotive engineering are as follows:

- use of recycled polymers (Fig. 13)

- reduction in the number of types of plastics

- replacing composite materials by

a) single-material systems

b) compatible material systems

- plastics with minimum quality loss during recycling

- multifunctional components 
The use of regenerative resources, for example for textiles or as reinforcing fibres in plastics, is currently being investigated.

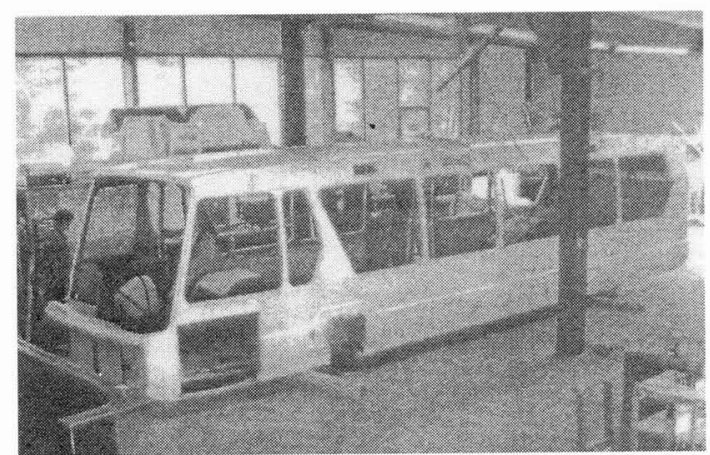

Fig. 12: Self-Supporting Bus Cell of FRP
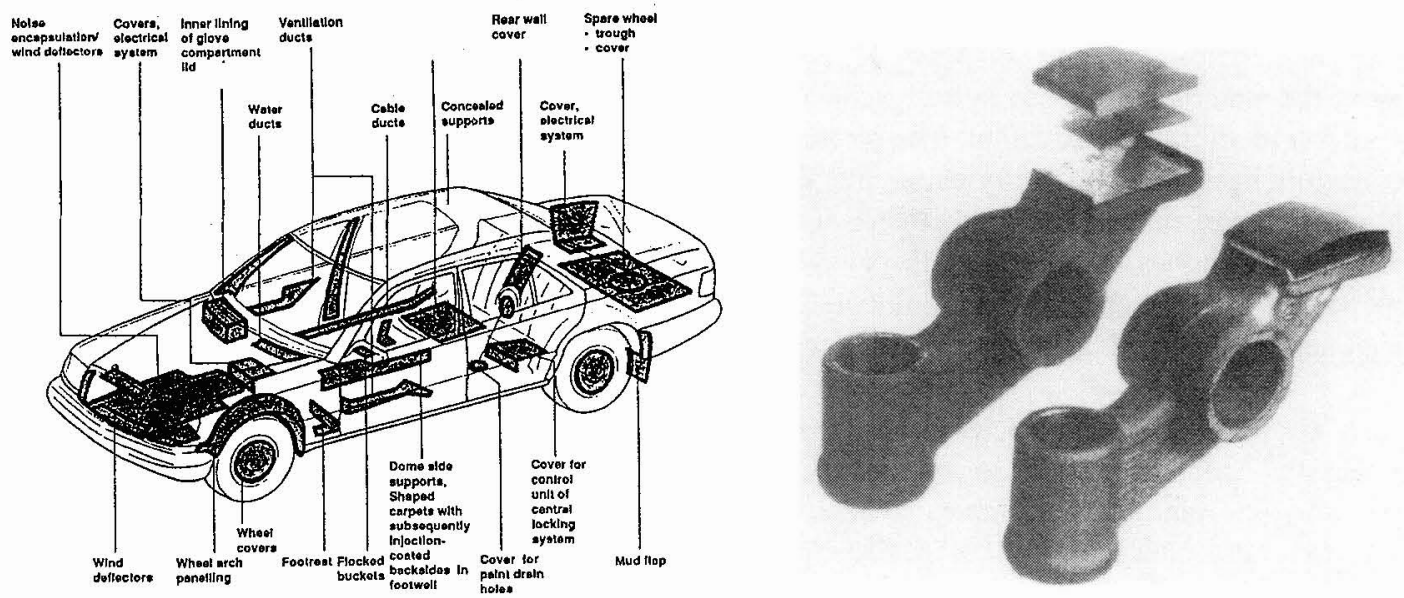

Fig. 13: Proposed use of recycling materials (1991)

Fig. 14: Rocker arms with ceramic rubbing block

\section{3 "New" materials}

It is not possible to consider all the materials - metallic, ceramic or polymeric - which are currently in the research stage, or to discuss their potential for applications in automobile manufacture. There are however certain materials which have been subjected to pre-production development and testing, or have already been applied in the mass production process. A small number of representative examples will be reviewed.

These materials are also subject to the criterion that they will only find application when they are able to provide cost reductions as well as improving on current or future requirements in comparison with conventional materials. The introduction of so-called "high-tech materials" at 
higher costs for reasons of image will be beyond the means of all mass-production automobile manufacturers for the foreseeable future.

The endeavor to utilize ceramic materials, with their undeniably interesting range of properties, in automobile manufacture has persisted for many years. The corrosion resistance, the resistance to oxidation at high temperatures, the capacity of resistance to wear and the low relative density of these materials make them especially attractive candidates for use in engine production (Fig. 14). Extensive series of experiments have been carried out with valves and turbine wheels for turbochargers, to name but two examples. Many of these components have achieved high operating performances. The current price of ceramic components is still higher compared to those with the presently applied materials. Nevertheless it could be attractive if the application of ceramics provides sufficient advantages. However, the materials engineers in the automobile industry must also consider factors other than material and component properties - for example the possibilities and costs of testing for purposes of quality assurance. This factor and problems with finishing in a large series production have prevented the use of ceramics for components in mass-production until now.

Another example of the application of a new material is provided by the use of a spring made from shape-memory alloy (SMA) for matching the shift smoothness at low and high oil temperatures in automatic transmissions. The multifunctionality of this material allowed it to be used to replace an expensive and bulky controller unit. In the meantime, however, a new design has produced a solution which does not require the use of this spring. The study of this material by our materials engineers has however lead to the recognition of a series of other interesting application possibilities. One of these is the use of SMA clamping sleeves, which make possible the reuse of chucking tools for drills (Fig. 15). These parts are currently being introduced into the fabrication process with noticeable cost advantages (Fig. 16).

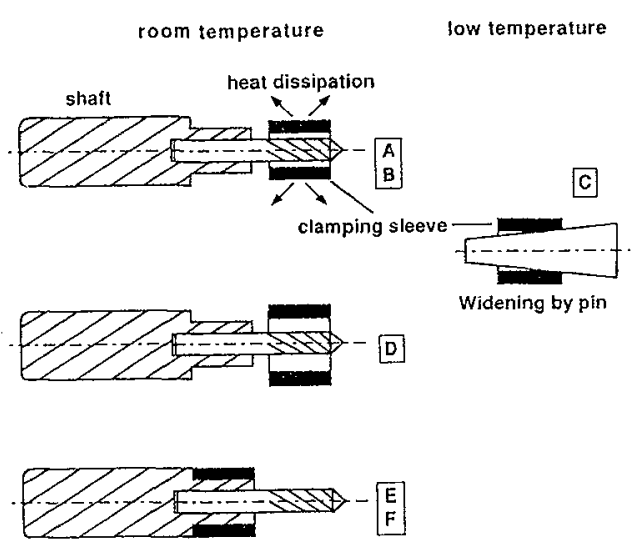

Fig. 15: Principal of Tool Clamping System with Shape-Memory Alloy

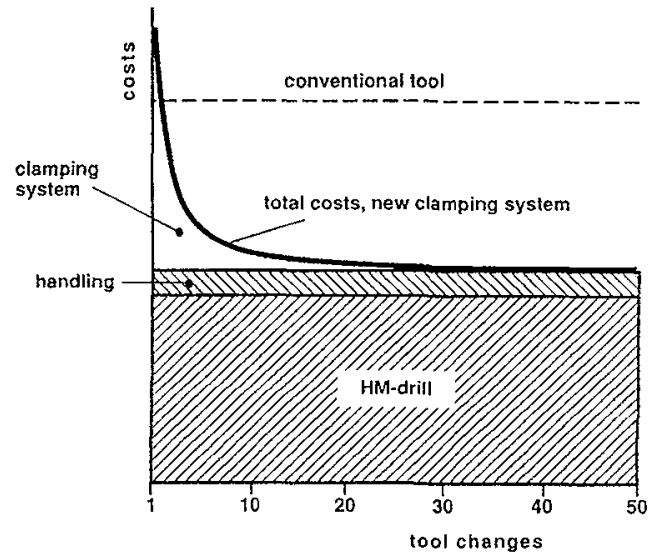

Fig. 16: Comparison of costs between conventional boring tool and new clamping system with shape-memory alloy 
Another, as yet extremely new class of materials currently opening up potential applications is that of the intermetallic phases. Although questions concerning processing and machining for mass production have not yet been finally resolved, the results of extensive series of experiments show that the introduction of this alloy in the area of e.g. diesel engine prechambers is likely. A cost advantage accrues from the use of this alloy, because it competes with Ni-base alloys and ODS alloys.

\section{SUMMARY}

1. Materials selection in the automotive industry is governed by the demands emerging from customers expectations and legal requirements. The development of materials application in the near future will be determined by ecological needs like consumption reduction and used vehicle disposal and by the necessity to reduce costs.

2. The present distribution of the materials in automobile manufacture with respect to weight will not change dramatically, even under altered legal and social contexts. The main reason for this is that ferrous-materials, and especially steel, will continue to play a dominant role in future due to the variability of their properties, their easy availability and their economic price-performance ratios. The continuing development potential possessed by this material even after more than 120 years of modern steel development remains a source of fascination to the materials engineer.

3. The demands for reduced consumption will lead to the use of an increasing proportion of aluminium, possibly at the expense of higher automobile prices. The proportion of plastics will also increase for the same reasons. Preconditions for this are the provision of suitable recycling and/or disposal methods, and a change in the way the public discussion over this point is conducted - the debate must become more factual and less emotional.

4. New, so-called "high-tech" materials will continue to find special applications in automobile manufacture, particularly when they are capable of offering multifunctional solutions. However, their specialization and usually higher cost condemn them to remain as materials for niche applications mostly in small series, with no real relevance in terms of weight.

\section{References}

[1] Ch. Schneider and W. Prange; Thyssen Technische Berichte, Heft 1 (1992) pp. 97 - 106

[2] B. Lee, M. Wenger and G. Pöschel in: Kunststoffe im Fahrzeugbau - Evolution statt Revolution, VDI-Gesellschaft Kunststofftechnik (ed.), Düsseldorf, 1992, pp. 161 - 174 